\title{
A Simulation Study Of Economic Production Quantity Lot Size To Kanban For A Single Line Production System Under Various Setup Times With Annual Setup Cost As Performance Metric
}

Terrence J. Moran, St. Bonaventure University, USA

Kevin Brayer, St. Bonaventure University, USA

\begin{abstract}
The Setup time variable was evaluated for the two systems (Kanban and EPQ) against the performance measure of annual setup cost. EPQ outperforms Kanban onsetup cost. The research helped clarify for practitioners whether EPQ might be more suitable than Kanban for their given situations.
\end{abstract}

Keywords: Production Systems; Kanban; Economic Production Quantity; Economic Order Quantity; EPQ; EOQ; Setup; Simulation

\section{INTRODUCTION}

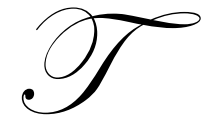

here are advantages to both Economic Production Quantity (EPQ) model and the Kanban model (Nicholas, 1998). The EPQ is a variation of the economic order quantity model (EOQ) but, unlike in the EOQ model where orders are received all at once, orders in the EPQ model are received gradually over time.

The objective of this study is to fill a research gap by evaluating EPQ to Kanban for a single line, multiproduct item production system under various setup times. The objective will be accomplished by utilizing simulation to evaluate Kanban and EPQ production systems. The primary variable is setup time. The performance measure is annual setup cost. This research will help practitioners determine the conditions under which the EPQ and the Kanban systems are more appropriate for them so that their companies could better compete in the competitive global marketplace.

The Arena (Kelton et al., 2002) simulation package will be used to carry out simulation of the Kanban and EPQ production systems and the results will be analyzed using statistical methods from Arena ${ }^{1}$. The performance metric used is setup cost, defined as costs incurred while preparing the production system for another product. Annual setup cost is measured as the product of the number of setups to produce annual demand of all products, time per setup, and hourly rate ( $\$ 60.00 /$ hour). The units of measures are dollars.

\section{LITERATURE REVIEW}

There has been very little research evaluating EPQ and Kanban in one study. Choi (1998) does some indirect comparisons while others (Louis, 1997; Mason, 1999; Morquecho, 1997; Newman, 1992) have done MRP

\footnotetext{
${ }^{1}$ Arena is a registered Trade Mark of Rockwell Software, In., Sewickley, PA. 
and Kanban/JIT comparisons that incorporate some aspects of EOQ versus Kanban. Jaber and Bonney (1999) and Jones (1991) have discussed some type of integration of EOQ and Kanban. Schonberger (1982), Monden (1983), and Hopp and Spearman (1996) have discussed the different systems separately, but did not compare one to the other.

\section{RESEARCH VARIABLE}

Setup time is the variable that is used to evaluate the EPQ and Kanban control systems. Setup time is the time to change a machine over to be ready to manufacture a product type.

\section{METHODOLOGY}

The simulation language to be used in this study is Arena (Kelton et al., 2002), a SIMAN based simulation package. For a complete treatment of SIMAN the interested reader is referred to Pegden et al. (1995). The Kanban and EPQ production systems and the results will be analyzed using statistical methods from Arena ${ }^{2}$. AQnnual setup cost is the performance metric.

\section{Research question and hypothesis}

In a station-to-station shop with setups, does a Kanban controlled or an EPQ controlled process have lower annual setup cost?

Table 1: Research design and combinations

\begin{tabular}{|l|l|l|}
\hline \multicolumn{1}{|c|}{ System } & \multicolumn{1}{|c|}{ Variable } & \multicolumn{1}{c|}{ Performance Metric } \\
\hline 1. EPQ & 1. Setup Time: $1,5,10,15,30,60$ Minutes & 1. Annual setup cost \\
\hline 2. Kanban & 2. Setup Time: $1,5,10,15,30,60$ Minutes & 2. Annual setup cost \\
\hline
\end{tabular}

\section{General Description of simulation models}

The Kanban and EPQ simulations emulate the manufacture of a finished product that needs no assembly. This study is a simulation of a serial flow shop with kanban container size of 5, 10, and 15 . The intent of using different container sizes is to enhance any differences between Kanban and EPQ, and to investigate changes as the size of the container increase.

A five-workstation simulation was chosen to reduce the complexity that occurs in a larger simulation. This requirement (five stations) is needed to fully test the methods of control. A review of the past literature demonstrated that a five-station flow line is adequate in representing the various real and hypothetical flow lines cited in literature (Yang, 2000).

\section{Kanban control simulation model}

The simulation model is a two-card Kanban system. There are two buffers between each pair of workstations. This study utilized a five-station Kanban system. A graphical representation of the Kanban simulation model is shown in Figure 1 (Gupta and Al-Turki, 1998).

\section{EPQ Control simulation model}

Figure 2 is a graphical representation of the WIP inventory arrangement between each pair of workstations of the EPQ simulation model. The process batch size specifies the number of units to be completed between setups. When the process batch is complete the workstation undergoes a setup for the next product in line.

\footnotetext{
${ }^{2}$ Arena is a registered Trade Mark of Rockwell Software, In., Sewickley, PA.
} 


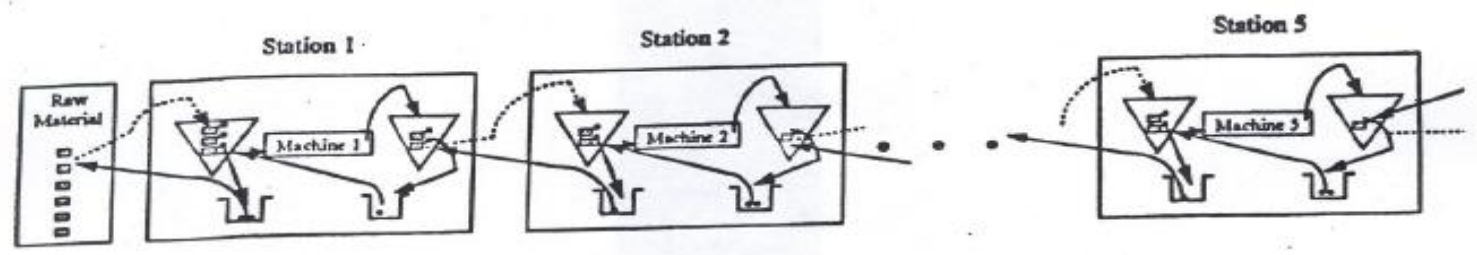

Figure 1: Kanban Simulation Model

(Gupta and Al-Turki, 1998).

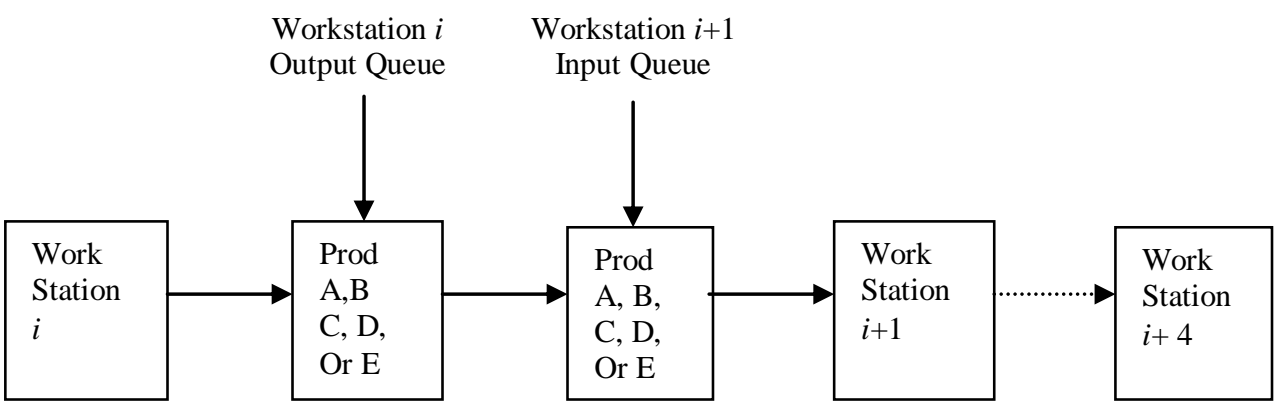

Figure 2: EPQ Simulation Model

\section{Statistical Technique}

Since this is an exploratory multi-factor study, analysis of variance (ANOVA) is considered appropriate. The intent of the study is not to determine the exact nature of the relationship between the independent and dependent variables, but to determine if a relationship exists. This information will be provided by ANOVA (Kelton, 2002).

The hypotheses are concerned with contrasting the effects of setup time on Kanban and EPQ individually.

Annual setup cost is the primary focus of the study.

The level of significance for statistical tests of primary factor and interaction effect is 0.05 . The alternatives for the statistical test for the primary and interaction effects are:

Ho: $\quad$ factor effect $=0$, the factor has no effect

Ha: factor effect $\neq 0$, the factor does have an effect

The decision rule is:

If $\mathrm{P}$ value $\geq 0.05$, conclude Ho

If $\mathrm{P}$ value $<0.05$, conclude $\mathrm{Ha}$ 
Table 2: Simulation Model Parameters

I. Factory environment/fixed assumptions applicable to both EPQ and Kanban

\begin{tabular}{|c|c|}
\hline Parameter & Values \\
\hline Demand & $\begin{array}{l}2000 \text { units a year for each product } \\
1 \text { year }=50 \text { weeks; } 1 \text { week }=5 \text { days } ; 1 \text { day }=24 \text { hours }\end{array}$ \\
\hline Setup Costs & $\$ 60.00$ per hour \\
\hline Annual Holding Cost Rate & $20 \%$ \\
\hline Production Cost & $\begin{array}{l}\$ 80.00 \text { per unit } \\
\text { Each of the } 5 \text { workstations adds } \$ 16.00 \text { of costs }\end{array}$ \\
\hline Processing Time & $\begin{array}{l}20 \text { minutes per part total } \\
4 \text { minutes per workstation, gamma distribution } \\
\alpha=2, \sigma^{2}=8\end{array}$ \\
\hline Number of Work Stations & 5 \\
\hline Number of Products & 5 \\
\hline \multicolumn{2}{|l|}{ II. EPQ assumptions and variables } \\
\hline Parameter & Values \\
\hline Setup Time (Primary variable) & $1,5,10,15,30,60$ minutes. With a gamma distribution, $\alpha=2$. \\
\hline Process Batch Size & $\begin{array}{l}\text { EPQ: } 84,188,266,325,460,651 \text { (based on EPQ formula, refer to Nicholas, } \\
\text { 1998). Batch sizes correspond to setup times of } 1,5,10,30 \text {, and } 60 \text { minutes } \\
\text { respectively. }\end{array}$ \\
\hline EPQ (Transfer Batch) & 1 unit \\
\hline \multicolumn{2}{|l|}{ III. Kanban assumptions and variables } \\
\hline Parameter & Values \\
\hline Setup Time (Primary variable) & $1,5,10,15,30,60$ minutes. With a gamma distribution, $\alpha=2$. \\
\hline Kanban Container Size & $5,10,15$ units \\
\hline Process Batch Size & $\begin{array}{l}\text { Number of production kanban: } 1 \text { kanban per work station } \\
\text { Number of withdrawal kanban: } 1 \text { kanban per work station } \\
\text { (based on kanban formula, refer to Nicholas, 1998). }\end{array}$ \\
\hline $\begin{array}{l}\text { Kanban (transfer batch), which is kanban } \\
\text { container size }\end{array}$ & 5,10 , and 15 units per kanban container \\
\hline
\end{tabular}

\section{Number of Replications}

The number of replications to obtain the desired precision is automatically calculated by the Arena software. The desired precision is a 95\% confidence that the estimated means are within $0.1 \%$ of the true mean on the Total Cost measure. Both the EPQ and Kanban simulations were utilized for this determination.

\section{Verification of EPQ and Kanban Simulation Model}

Verification entails ensuring that the logic of the model is good. To accomplish this, the logic constructs selected for the modules that were used were compared to the system parameters delineated in Table 2. It was determined that the model met these parameters.

In addition, further verification was accomplished by running the simulation with animation. As stated, "Animation is often very useful during the verification and validation phases because it presents the entire system being modeled as it operates" (Kelton et al., 2002). It was determined that with the animation that the model appeared to operate very similar to the way the system was described.

The Kanban simulation was run for a setup time of 5 minutes and kanban container size of 10. It was run for 51 replications. The results were analyzed and the values had face validity. It was therefore concluded validated. 


\section{Research Caution on Comparing EPQ to Kanban System}

This study is making an evaluation of the Kanban and EPQ control systems. The EPQ and Kanban systems are two different systems and direct comparisons can be difficult to make. Since these are two different systems, direct statistical analysis between the systems cannot be made. However, general overview statements can be made when making a comparison between the two systems.

A statistical analysis of effect of setup time on Kanban system and EPQ system will be made in this research. These are made separately. A general overview statement can and will be made comparing the two systems in the conclusion.

\section{RESULTS}

Once the simulation model was tested and verified, data was collected to analyze the Kanban and EPQ systems. The model provided the data on the performance measure of annual setup cost. Units of measure are dollars.

\section{Results of EPQ/Kanban, Total Time vs. Setup Time}

Does setup time affect the annual setup cost of the Kanban controlled process vs. EPQ system?

The mean values of the annual setup cost are plotted for each of the Kanban systems (5, 10, and 15) and EPQ system in Figure 3. As Figure 3 shows, EPQ annual setup cost is less than each of the Kanban Systems (5, 10, and 15). Also, as the setup time increases the difference of the annual setp cost increases between EPQ and each of the Kanban systems $(5,10$, and 15). It can be generally stated that increasing the setup time increases the difference in the annual setup cost between the Kanban controlled and EPQ controlled processes. Figure 3 supports this conclusion.

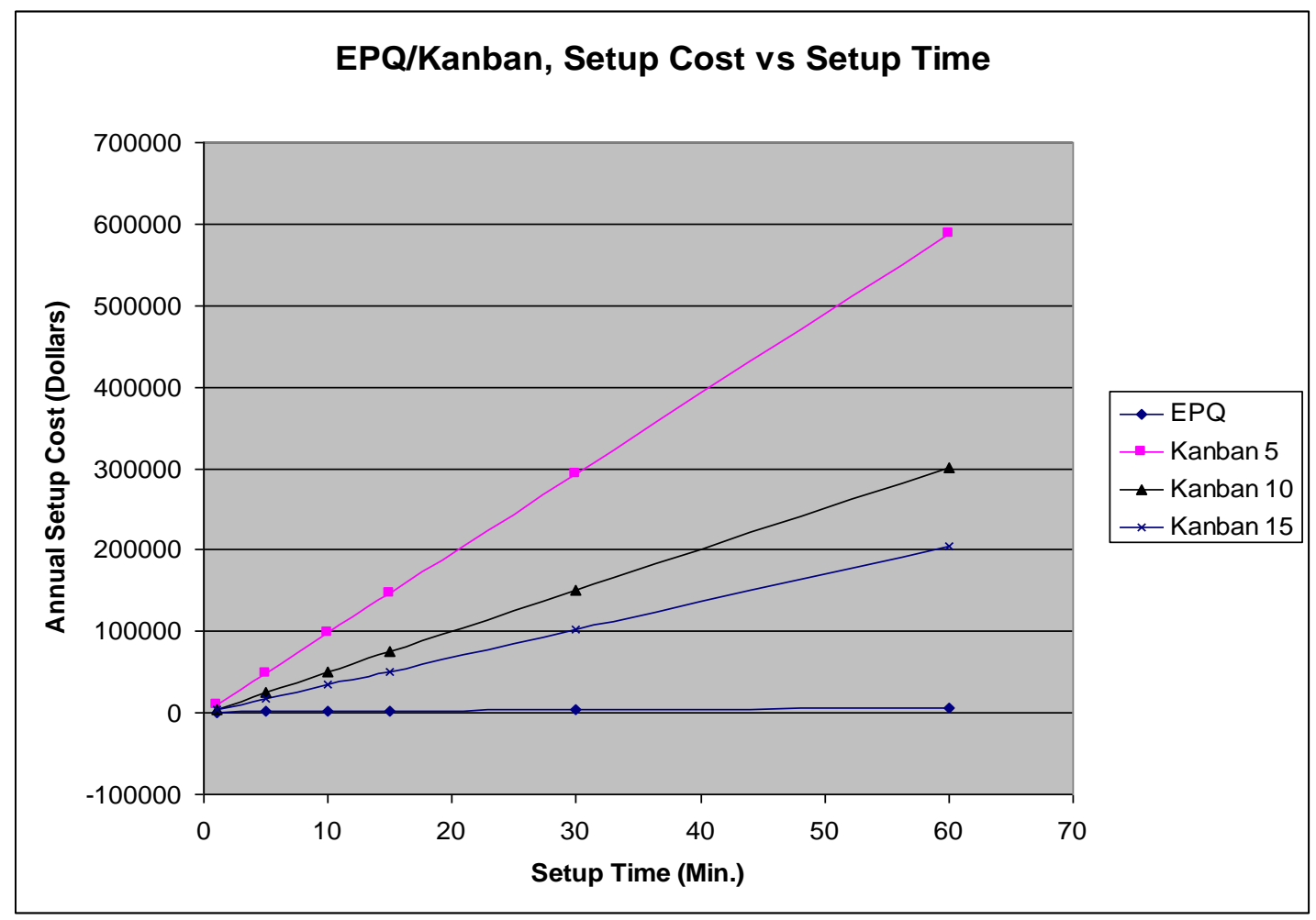

Figure 3: EPQ/Kanban, Annaul Setup Cost vs Setup Time 
This lower annual setup cost for the EPQ system vs. Kanban can be explained that as setup time increase the EPQ lot sizes become larger than Kanban systems. With the larger lot size there will be fewer setup changes and therefore lower annual setup costs.

\section{SUMMARY}

This research is exploratory with the objective of testing theory and making evaluations of Kanban and EPQ control methods. The research studied the effects of the variable setup time on annual setup cost. The model simulated a multi-product, station-to-station shop with setups. The research question addressed was, "In a stationto-station shop with setups, does a Kanban controlled or an EPQ controlled process have lower annual setup cost?"

\section{Effect of Setup Time between Kanban and EPQ}

The setup time variable was evaluated for the two systems (Kanban and EPQ) against the performance measures of annual setup cost. Even though a direct statistical comparison cannot be made between Kanban and EPQ some general conclusions can be made. The results of these analyses are summarized in Table 3.

Table 3: Kanban vs. EPQ summary of the results Variable Setup Time

\begin{tabular}{|c|c|c|c|c|}
\hline $\begin{array}{c}\text { Performance } \\
\text { Measure }\end{array}$ & EPQ & Kanban 5 & Kanban 10 & Kanban 15 \\
\hline Annual Setup Cost & EPQ superior to all & EPQ superior & EPQ superior & EPQ superior \\
\hline
\end{tabular}

\section{CONCLUSIONS AND MANAGERIAL IMPLICATIONS}

By evaluating the Kanban and EPQ in a single study, this research offers managers a better understanding of choosing the correct production system for their multi-product production line. This contribution is significant because it evaluates the different systems and provides insights on selecting the correct system for a multi-product production system.

The expected finding for the research question was that when setup times are high (greater than 30 minutes), EPQ will have lower annual setup costs. It was expected that Kanban will have lower annual setup cost at some setup time of less than 15 minutes. If Kanban was found not to have a lower annual setup cost than EPQ, even below a setup time of 15 minutes, then this would have been a more remarkable finding because it would go against common intuition.

On the measure of total annual setup cost while varying setup time, EPQ even outperforms Kanban at setup times of less than 15 minutes. In fact EPQ outperforms Kanban for all setup times. This is a remarkable finding, because it goes against common beliefs.

An advantage of the Kanban system is that it has some more flexibility than EPQ. It is a method of adapting to changes due to problems and demands by having all processes produce the necessary product at the necessary time. An advantage of the EPQ is that it has lower overall annual setup cost. This is partially accomplished by producing in larger lots and therefore reduces the number of setups required and the resultant setup costs.

\section{SPECIFIC LIMITATIONS AND SUGGESTIONS FOR FUTURE STUDY}

The major focus of this research was the impact of setup time on EPQ and Kanban systems. Therefore some of the factors known to affect performance but that are outside the realm of the research had to be controlled. Three areas that were held constant in this research and would be of interest of further study would be demand, number of workstations, and number of products.

Demand: It is not the intention of this research to study the impact of demand variation on performance. We assumed that the demand was constant at 2000 parts a year for each of the products. An area of future research would be to vary demand. 
Number of workstations: The simulation utilized a five-workstation system chosen to reduce the complexity that occurs in a larger simulation. An area of future research would have a simulation of larger than 5 workstations.

Number of products: The product mix was held constant at 5 products. This is not realistic in the real world where product mixes change. An area of future study would have a variety of product mixes.

\section{AUTHOR INFORMATION}

Dr. Terrence J. Moran is an Assistant Professor in the school of business at St. Bonaventure University. Research interests include Operations Management - waiting line studies, and simulation studies of production systems. School of Business, St. Bonaventure University, St. Bonaventure, NY 14778.

Professor Kevin Brayer is a marketing instructor in the school of business at St. Bonaventure University. School of Business, St. Bonaventure University, St. Bonaventure, NY 14778.

\section{END NOTES}

1. Abdou, G. and S. P. Dutta. "A Systematic Simulation Approach to the Design of JIT Manufacturing Systems." Journal of Operations Management 11 (1993): 225-38.

2. Choi, S. Material flow system integration in EOQ, ELSP, and Kanban Production. Columbia: University of Missouri-Columbia, 1998.

3. Gupta, S.M. and Y.A.Y. Al-Turki. "The Effect of Sudden Material Handling System Breakdown on the Performance of a JIT System.” International Journal of Production Research 36 n.s. 7 (1998): 1935-60.

4. Hopp, W. J. and M. L. Spearman. Factory Physics: Foundations of Manufacturing Management. Chicago: Irwin, 1996.

5. Jaber, M. and M. Bonney. "The Economic Manufacture/Order Quantity (EMQ/EOQ) and the Learning Curve: Past, Present, and Future." International Journal of Production Economics 59 (March 1999): 93102 .

6. Jones, D. “JIT and the EOQ Model: Odd Couple No More!” Management Accounting 72 (Feb. 1991): 5458.

7. Kelton, D., R. Sadowski, and D. Sadowski. Simulation with Arena, $2^{\text {nd }}$ Ed. New York: McGraw-Hill, 2002.

8. Krajewski L., B. King, L. Ritzman, and D. Wong. "Kanban, MRP, and Shaping the Manufacturing Environment." Management Science 33 n.s.1 (1987): 39-57.

9. Louis, R. S. Integrating Kanban with MRPII: Automating a Pull System for Enhanced JIT Inventory Management. Portland: Productivity Press, 1997.

10. Mason, P. "MRPII and Kanban Formulae.” Logistics Focus (April 1999): 19-23.

11. Martinez, F. M. and L. Bedia. "Modular Simulation Tool for Modeling JIT Manufacturing." International Journal of Production Research 40 n.s. 7 (2002): 1529-47.

12. Morquecho, J. "A Comparative Analysis of MRP and Kanban.” Thesis, California Polytechnic State University, 1997.

13. Monden, Y. Toyota Production System: An Integrated Approach to Just-In-Time, $2^{\text {nd }}$ Ed. Norcross, Georgia: Engineering and Management Press, 1993.

14. Newman, W. "Manufacturing Planning and Control: Is There One Definitive Answer?" Production and Inventory Management Journal 33 (1992): 50-54.

15. Nichols, J. M. Competitive Manufacturing Management. New York: Irwin McGraw-Hill, 1998.

16. Pegden, C.D., R. Shannon, and R. Sadowski. Introduction to Simulation Using SIMAN, 2nd ed., New York: McGraw-Hill, 1995.

17. Putt, J. W. "A Comparison of Production Control Methods for a Serial Flow Shop with Setups." Ph.D. diss., University of Georgia, 1995.

18. Schonberger, R.J. Japanese Manufacturing Techniques. New York: Free Press, 1982.

19. Yang, K. K.. "Managing a Flow Line with Single-Kanban, Dual-Kanban, or Conwip." Production and Operations Management 9 n.s. (2000): 349-66. 


\section{NOTES}

